\title{
Suicide mortality in Greater London: Changes during the past 25 years
}

\author{
R. D. T. FARMER, T. D. PRESTON, AND S. E. M. O'BRIEN \\ From the Westminster Medical School, London
}

SUMMARY Suicide mortality in the area now administered by the Greater London Council was assessed for three five-year periods 1949-53, 1959-63, and 1969-73. For each of the periods the standard mortality ratio (SMR) for suicide in various boroughs was calculated for men and women separately. The boroughs with high SMRs for men were constant. There was a pronounced change in the geographical distribution of high mortality among women. These findings support the hypothesis that the determinants of suicide differ between the sexes.

The south-east of England has the highest suicide rate in the United Kingdom and within this region the Greater London conurbation has a higher rate than the surrounding areas (Registrar General). Sainsbury (1955) investigated the epidemiology of suicide in the then administrative county of London. He showed that there were substantial variations in rates between the 29 boroughs. Boroughs with a high rate for men did not necessarily have a high rate for women. He demonstrated that the variation in rates correlated with certain social and demographic characteristics of the individual boroughs and that these were social class mix, mobility, population density, and the level of unemployment.

Since Sainsbury's study there have been fewer suicide deaths in England and Wales, but there has been an increase in non-fatal self poisoning (Alderson, 1974). Much of the decline in suicide rates is explained by fewer cases of poisoning by domestic gas, particularly among elderly people (Dean et al., 1976; Kreitman, 1976).

A difficulty inherent in studying the epidemiology of suicide is that the term 'suicide' does not represent a diagnosis of a physical disorder leading to death; it is the opinion of a third party as to the intent of the deceased when taking self-destructive action. The way in which such an opinion is arrived at varies between different legal systems; it may also vary between individual coroners (Barraclough, 1972; Bolander, 1972; Ross and Kreitman, 1975; World Health Organisation, 1975). This point is emphasised by Patel (1974) who suggested that coroners are reluctant to return a verdict of suicide unless it is quite unavoidable. Adelstein and Marden (1975) suggested that the true incidence of suicide in
England and Wales was better estimated by combining 'open verdicts' with suicide.

This paper reports trends in certified suicide mortality within the area now administered as Greater London.

\section{Methods}

This study is based on an investigation of 'suicide' mortality records analysed according to the area of residence of the deceased within Greater London. Most of the data were obtained from the Annual Statistical Reviews (Registrar General) for the relevant years; additional information was provided in the borough analysis of death made by the Office of Population Censuses and Surveys but not widely published (SD 25 forms). In 1968 a change in ICD coding resulted in a new category being used, BE 50 (all other external causes). This category includes all 'open verdicts'. Mortality from 'suicide' and 'all other external causes' combined was analysed in the same way as 'suicide' in the third period studied. This was done to overcome some of the objections to the use of certified suicide as the sole indication of suicide mortality.

Three periods of time were studied in detail: 1949-53, 1959-63, and 1969-73. These were chosen because they centred on the last three decennial censuses. The censuses provided detailed data on the size and structure of local populations and also gave other detailed demographic information.

Direct comparison between pre- and post-1966 data was not possible because a reorganisation of local government boundaries in the London area took place in the mid 1960s (Fig. 1). This reorganisa- 


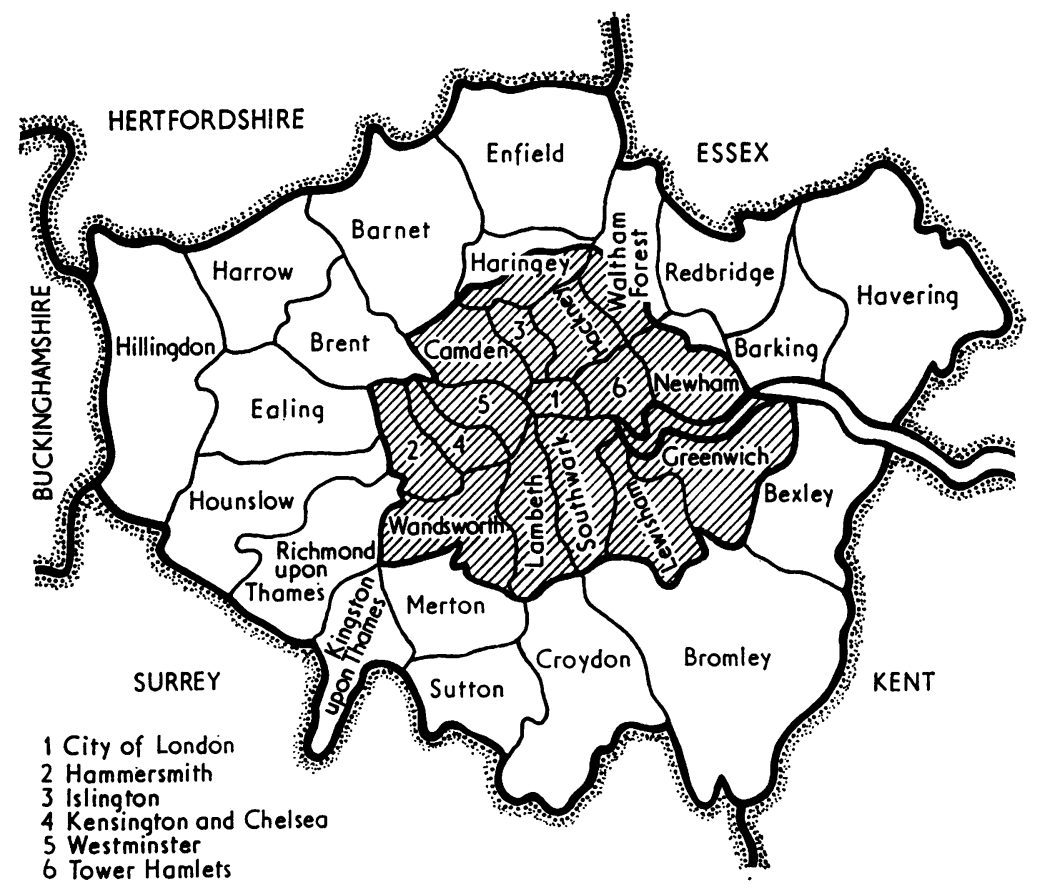

Fig. 1 Administrative county of London until 1966.

tion amalgamated the administrative county of London with certain boroughs, urban districts, and rural districts that had previously been part of the home counties, to form the present Greater London Council area In this study populations and numbers of certified suicide deaths for the years 1949-51 and 1959-61 were assigned within the current borough boundaries of Greater London. This produced comparative data for specific geographical areas. The City of London has a population of about 4500; because of its small size and the small numbers of suicides, data were combined with those from Westminster.

Suicide is a relatively rare event. Greater London has a different age structure from the rest of the country inasmuch as there are proportionately more young adults, therefore comparison of mortality using crude rates is not appropriate. Indirect standardisation for differences in age structure using the standard mortality ratio (SMR) allows a more valid comparison of mortality to be made. The SMRs in this study were calculated from the England and Wales base rates for the relevant years.

The significance of the SMRs was assessed using the $x^{2}$ test. This enabled the boroughs that were different from national experience to be identified, but it was not possible to test for the significance of differences between boroughs. Consequently the boroughs that were significantly different from England and Wales were analysed according to the size of the SMR alone.

\section{Results}

The average annual age specific suicide death rates for England and Wales during the three periods are shown in Fig. 2. Death rates for men were higher than those for women at all ages during all three $\stackrel{\circ}{\circ}$ periods. There was a rise in rates with increasing age. Although the rates for young adults were low, 3 . suicide accounted for just under $10 \%$ of all deaths in the 15-24-year age group during the period 1969-73.

Since 1949-53 there has been a marked decrease in the number of suicide deaths in men over the age of 45 years. There was an increase in death rates in men under 45 years between 1949 and 1953, and again 0 between 1959 and 1963, followed by a decrease. N Rates for women increased between 1949 and 1953 N్ and again between 1959 and 1963 in all age groups. 0 By 1969-73 they had fallen below the 1949-53 levels in all age groups over 40 years, but below that they remained higher than in 1949-53. 


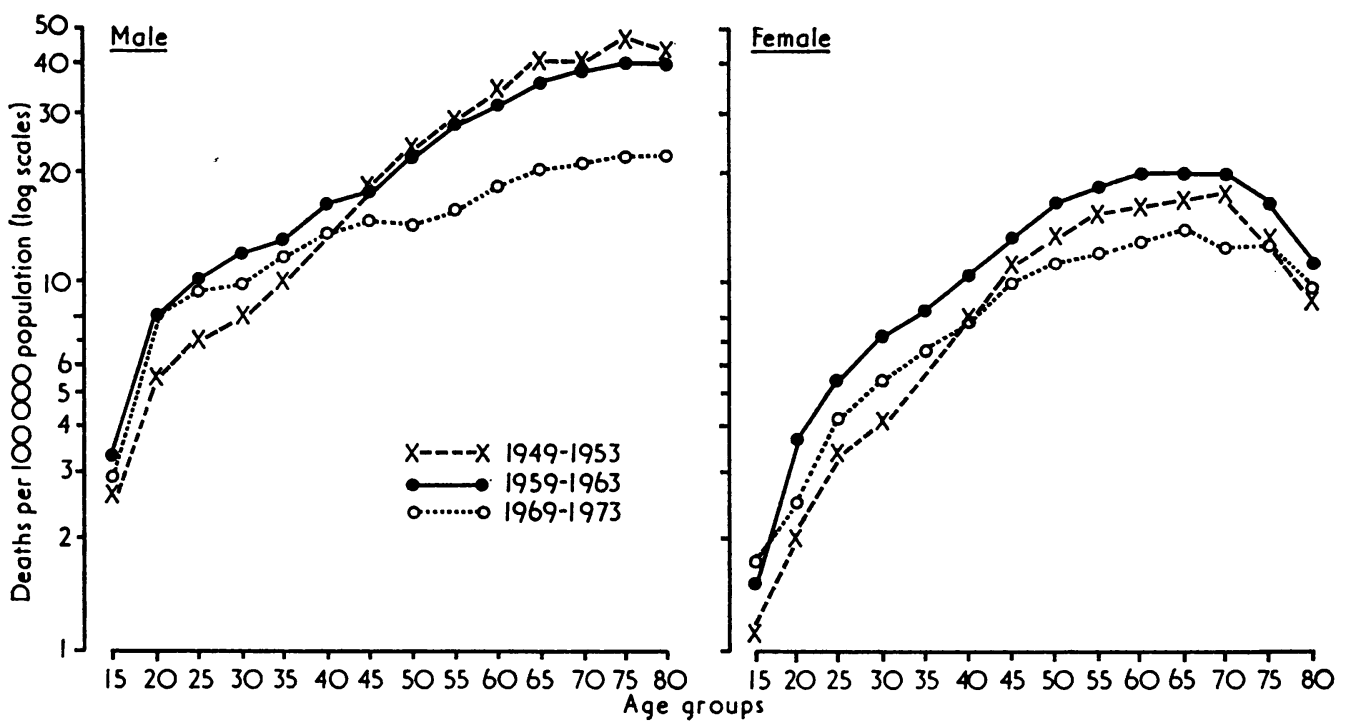

Fig. 2 Five-year average annual age-specific death rates from suicide (England and Wales).

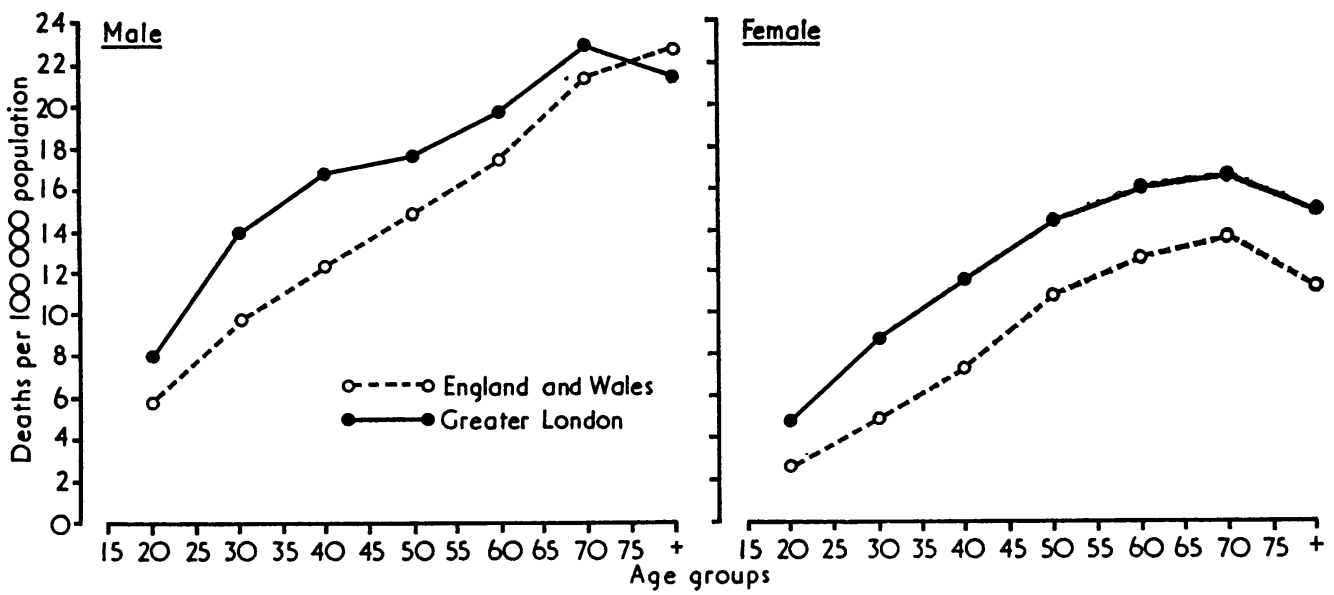

Fig. 3 Five-year average annual age-specific death rates from suicide for 1969-73.

In Fig. 3 the average annual age specific suicide death rates during the period 1969-73 for England and Wales are compared with those for Greater London. The Greater London rates are higher in all age groups and for both sexes, with the exception of men over 75 years. Proportionately greater differences are seen in young people than in other age groups.

Table 1 shows the SMR for suicide in Greater London during the three periods.
During the period 1949-53 mortality from suicide in Greater London was little different from the rest of the country. The subsequent divergence from national experience is more marked in women than in men. Table 2 shows the range of SMRs observed in individual London boroughs.

Whereas in men the range has changed little in time, that for women has increased substantially. Table 3 shows the boroughs with SMRs that were significantly different from national experience. The 
Table 1 SMR for suicide in Greater London (base rates: England and Wales for the same three periods).

\begin{tabular}{lcll}
\hline Period & Men & Women & Both sexes \\
\hline $1949-53$ & 98 & 103 & 100 \\
$1959-63$ & 113 & 125 & 118 \\
$1969-73$ & 122 & 140 & 130 \\
\hline
\end{tabular}

Table 2 Ranges of SMR observed in the London boroughs during three five-year periods (base rates England and Wales for the periods specified)

\begin{tabular}{llll}
\hline Period & Men & Women & Both sexes \\
\hline $1949-53$ & $41-197$ & $42-176$ & $45-189$ \\
$1959-63$ & $54-217$ & $69-232$ & $61-222$ \\
$1969-73$ & $39-227$ & $65-337$ & $58-277$ \\
\hline
\end{tabular}

SMRs for men in Westminster and the borough of Kensington and Chelsea have been consistently high and for women have increased remarkably during the period in both boroughs.

In Fig. 4 the four highest ranking boroughs for each period are shown. The areas with the highest mortality rates for men have not changed since 1949-53. By contrast there has been a change in the areas of high suicide mortality in women. During the first period Camden ranked first and Haringey was third. Richmond was among the first four during the $D$ 1959-63 period but Haringey was not. During 1969-73 Hammersmith had become one of the highest ranking boroughs for suicide in women.

The ICD category 'all other external causes' $\overrightarrow{\bar{F}}$ (BE 50) comprises homicide, acts of war, legal intervention, and injury (either accidentally or purposely inflicted); $75 \%$ of deaths were in the last group. Thus ICD BE 50 approximates to 'open verdicts' and its inclusion with suicide could $\triangle$ meet some of the objections to suicide raised by $\%$ Adelstein and Marden (1975).

The SMR for 'all other external causes' ranked the boroughs similarly to the SMR for 'suicide' for men. In women there was a significant difference between the ranking of the boroughs for the two causes using the Spearman's rank correlation coefficient.

The boroughs were ranked by SMR for suicide and by certain demographic characteristics, and $\beth$ correlations were tested using the Spearman's rank o correlation coefficient. Table 4 shows the correlationg that were significant at less than $5 \%$.

There were differences between men and women in the demographic variables associated with suicide mortality in boroughs. High suicide mortality 画

Table 3 GLC boroughs which had SMRs for suicide that differed significantly from 100 at the $0 \cdot 1 \%$ level

\begin{tabular}{|c|c|c|c|c|c|c|}
\hline \multirow{2}{*}{ Quinquennium } & & \multicolumn{2}{|l|}{ Men } & \multicolumn{2}{|l|}{ Women } & \multirow{2}{*}{ 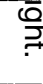 } \\
\hline & & Borough & $S M R$ & Borough & $S M R$ & \\
\hline \multirow[t]{2}{*}{ 1949-53 } & Low & $\begin{array}{l}\text { Hillingdon } \\
\text { Bromley } \\
\text { Hounslow } \\
\text { Ealing } \\
\text { Brent } \\
\text { Harrow }\end{array}$ & $\begin{array}{l}41 \\
47 \\
48 \\
50 \\
54 \\
67\end{array}$ & $\begin{array}{l}\text { Hounslow } \\
\text { Ealing } \\
\text { Redbridge }\end{array}$ & $\begin{array}{l}43 \\
49 \\
64\end{array}$ & \\
\hline & High & $\begin{array}{l}\text { Hammersmith } \\
\text { Kensington and Chelsea } \\
\text { Camden } \\
\text { Westminster }\end{array}$ & $\begin{array}{l}129 \\
191 \\
192 \\
197\end{array}$ & $\begin{array}{l}\text { Chelsea } \\
\text { Haringey } \\
\text { Camden } \\
\text { Westminster }\end{array}$ & $\begin{array}{l}148 \\
164 \\
176 \\
177\end{array}$ & \\
\hline \multirow[t]{2}{*}{$1959-63$} & Low & $\begin{array}{l}\text { Bromley } \\
\text { Havering } \\
\text { Waltham Forest }\end{array}$ & $\begin{array}{l}55 \\
63 \\
71\end{array}$ & Kingston & 50 & \\
\hline & High & $\begin{array}{l}\text { Wandsworth } \\
\text { Haringey } \\
\text { Southwark } \\
\text { Hackney } \\
\text { Hammersmith } \\
\text { Lambeth } \\
\text { Camden } \\
\text { Kensington and Chelsea } \\
\text { Westminster }\end{array}$ & $\begin{array}{l}128 \\
132 \\
132 \\
136 \\
164 \\
166 \\
200 \\
213 \\
217\end{array}$ & $\begin{array}{l}\text { Wandsworth } \\
\text { Southwark } \\
\text { Redbridge } \\
\text { Croydon } \\
\text { Barnet } \\
\text { Richmond } \\
\text { Camden } \\
\text { Westminster } \\
\text { Kensington and Chelsea }\end{array}$ & $\begin{array}{l}132 \\
138 \\
142 \\
145 \\
151 \\
156 \\
206 \\
213 \\
232\end{array}$ & \\
\hline \multirow[t]{3}{*}{ 1969-73 } & Low & Havering & 39 & & & \\
\hline & High & $\begin{array}{l}\text { Haringey } \\
\text { Southwark } \\
\text { Wandsworth } \\
\text { Camden } \\
\text { Lambeth } \\
\text { Hammersmith } \\
\text { Westminster } \\
\text { Kensington and Chelsea }\end{array}$ & $\begin{array}{l}137 \\
172 \\
172 \\
175 \\
178 \\
205 \\
215 \\
227\end{array}$ & $\begin{array}{l}\text { Croydon } \\
\text { Camden } \\
\text { Ealing } \\
\text { Brent } \\
\text { Kingston } \\
\text { Southwark } \\
\text { Wandsworth } \\
\text { Lambeth } \\
\text { Richmond } \\
\text { Hammersmith } \\
\text { Kensington and Chelsea } \\
\text { Westminster }\end{array}$ & $\begin{array}{l}137 \\
150 \\
150 \\
157 \\
163 \\
165 \\
169 \\
171 \\
172 \\
186 \\
332 \\
337\end{array}$ & \\
\hline & & England and Wales & 100 & & 100 & \\
\hline
\end{tabular}



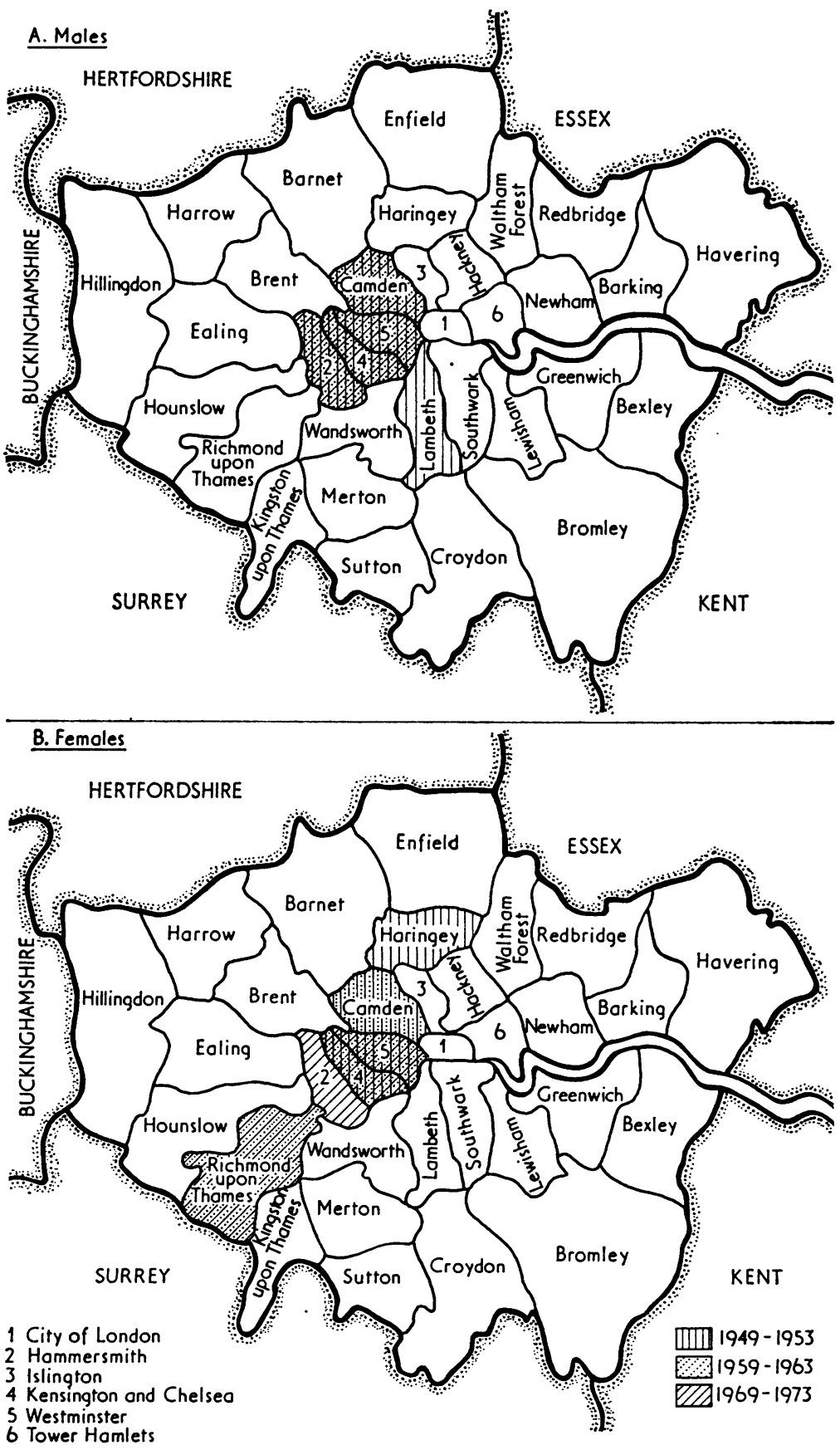

Fig. 4 Greater London showing City of London and boroughs. 
Table 4 Demographic variables that had significant correlations with suicide mortality in London boroughs during the period 1969-73. Correlations were tested using the Spearman's rank correlation coefficient: only those significant at less than $5 \%$ are shown

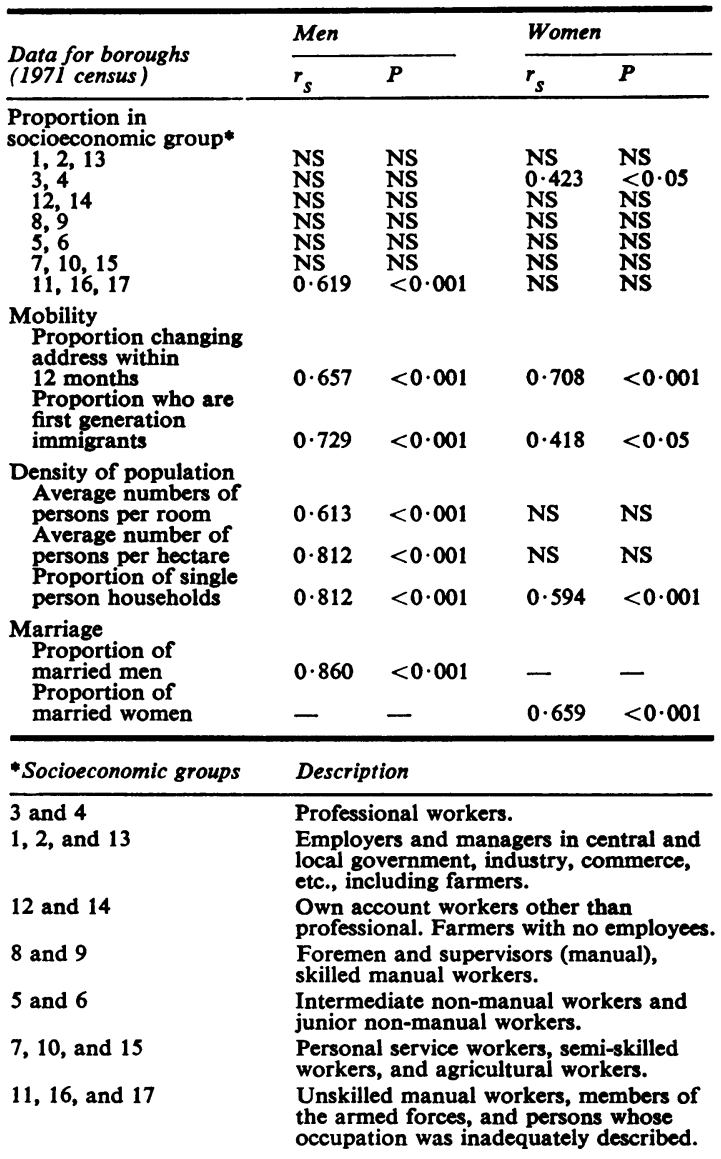

men was associated with a large number of unskilled manual workers, high density population, greater mobility, a high proportion of single person households, and a low incidence of marriage. High suicide mortality in women was associated with a large number of persons in professional employment, greater mobility, a high proportion of single person households, and a low incidence of marriage.

\section{Discussion}

Suicide is not a common cause of death, nevertheless it makes an important contribution to the total death rates in persons aged between 15 and 29 years. Recent trends have been for it to become less common; it would seem that much of this decline in mortality has been caused by the withdrawal of coal gas from domestic supply. Some of the changes however, may be the result of variations in certification practice.

Suicide mortality in Greater London has diverged from national levels since 1949-53. Much of the increase in the SMRs for Greater London is accounted for by the extremely high level of suicide mortality in the central boroughs. The fact that the areas with high mortality are different for men and women, and that for women there has been a change in the areas exhibiting high SMRs for suicide o suggests that the factors influencing high suicide $\vec{\nabla}$ mortality vary between the sexes.

Two alternative hypotheses may be proposed: either the social factors that precipitate suicide are more common in certain boroughs than in others and that these have become more prevalent in London during the last 25 years, or that people likely to kill themselves tend to concentrate in the central part of London. It is also quite possible that both of these factors operate together to produce the patterns described. The first hypothesis requires that certain factors affect a very small proportion of the $\mathrm{e}$ population to cause people to end their lives. It quite possible that unemployment, for example, in some people sufficiently depressing for them to feel that life is not worth living. However, in the best $\mathbb{\perp}$ of economic circumstances the suicide rate is $\vec{\theta}$ fraction of the unemployment rate. Even taking into. $\exists$ account a combination of demographic variables associated with suicide the number of persons affected by these is considerably in excess of the number committing suicide. It may be possible to identify risk factors from the systematic investigation of individuals but the type of data presented here cannot substantiate a causal hypothesis.

The most consistent findings in the boroughs with high mortality are an extremely high proportion of people who had changed their residence within a year of the last census, a large proportion of single person households, and a low incidence of marriage. All of these are indices of social disorganisation. These would support the hypothesis that certain areas attract certain types of person and it is possible that these persons may constitute a high risk group. Some of the demographic variables did not correlate with mortality in both sexes. Thus there was higher mortality in men in boroughs with high density housing and a high proportion of persons in socioeconomic groups 11,16 , and 17 , but socioeconomic groups 11,16 , and 17 also correlated with high density housing. Mortality in women correlated N with the proportion of the population in socio- 0 economic groups 3 and 4 . It has been shown elsewhere that suicide in men is relatively more common $\stackrel{\mathbb{D}}{\mathbb{D}}$ in lower social class areas and the converse is $\stackrel{?}{?}$ 
demonstrated in women.

The geographical distribution of suicide mortality may be determined by the attractiveness of the borough to certain high risk individuals. The risk factors for men are probably different from those for women.

The authors are grateful to the Library Staff of the Office in Population Censuses and Surveys for their assistance in finding essential data. Mrs J. Goodwin, Lecturer in Medical Statistics, Westminster Medical School, provided valuable statistical advice.

Reprints from R. D. T. Farmer, Department of Community Medicine, Westminster Medical School, Page Street Wing, Westminster Hospital, 17 Page Street, London SW1P 2AP.

\section{References}

Adelstein, A., and Marden, C. (1975). Suicides: 19611974. Population Trends, 2, 13-18.
Alderson, M. R. (1974). Self-poisoning-what is the future? Lancet, 1, 1040-1043.

Barraclough, B. M. (1972). Are the Scottish and English suicide rates really different? British Journal of Psychiatry, 120, 267-273.

Bolander, A. M. (1972). Suicide and Attempted Suicide, pp. 57-88. Nordiska Bokhandelns Förlag: Stockholm.

Dean, G., Adelstein, A., and Spooner, J. (1976). Suicide and self poisoning in Great Britain and Ireland. International Journal of Epidemiology, 5, 145-151.

Kreitman, N. (1976). The coal gas story. British Journal of Preventive and Social Medicine, 30, 86-93.

Patel, N. S. (1974). A study on suicide. Medicine, Science, and the Law, 14, 129-136.

Registrar General. Annual Statistical Review (for various years). HMSO: London.

Ross, O., and Kreitman, N. (1975). A further investigation of differences in the suicide rates of England and Wales and of Scotland. British Journal of Psychiatry, 127, 575-582.

Sainsbury, P. (1955). Suicide in London: An Ecological Study. Maudsley Monographs. Chapman and Hall: London.

World Health Organisation (1975). Suicide statistics: the problem-of comparability. Chronicle of the World Health Organisation, 29, 188-193. 